\title{
Experimentos iniciais da cromatografia gás-sólido com desenvolvimento por eluição
}

\author{
Carol H. Collins \\ Instituto de Química, Universidade Estadual de Campinas - UNICAMP, \\ Cep 13083-970, Campinas, SP, Brasil \\ e-mail:chc@iqm.unicamp.br
}

\section{Resumo}

Sistemas fechados e pressurizados para o manuseio de gases foram utilizados para a separação, identificação e, eventualmente, a quantificação de gases e compostos voláteis desde o início do século vinte, porém principalmente com desenvolvimento por deslocamento. Na década de 40 do século vinte, alguns pesquisadores realizaram alguns experimentos empregando o desenvolvimento por eluição, que logo foi usado para iniciar a cromatografia gás-sólido, ainda utilizado hoje.

Palavras-chave

História da cromatografia; cromatografia gasosa; cromatografia gás-sólido; desenvolvimento por eluição.

\section{Early experiments with elution in gas-solid chromatography}

\section{Abstract}

Pressurized systems to handle gases were used for separation, identification and, eventually, quantification of gases and volatile compounds from the beginnings of the $20^{\text {th }}$ century, principally with displacement development. In the 40's of the last century, some researchers began to experiment with development by elution, which led to the start of the gas-solid chromatography still used today.

Keywords

History of chromatography; gas chromatography; gás-solid chromatography; elution development.

Nos anos iniciais do século vinte, a passagem de misturas de gases em sistemas fechados, pressurizados e com temperaturas controladas foi descrita por diversos pesquisadores, sendo que somente poucos destes reconheceram que o processo que eles descreveram foi o de cromatografia gás-sólido, com desenvolvimento por análise frontal, isto é, com aplicação contí- nua da amostra que também servia como fase móvel, ou por deslocamento, no qual uma substância com mais afinidade pela fase estacionária foi aplicada para forçar a amostra a andar através da coluna, sendo que o componente menos retido saia primeiro, seguido pelos próximos, em sequência até, no fim, sair o deslocador no final da análise ${ }^{[1]}$. Por outro lado, o processo de elui- 
ção, descrito para a cromatografia líquido-sólido pelo russo M. S. Tswett em $1906^{[2]}$, foi bem aceito por todos os pesquisadores que aplicaram esta técnica para suas separações, principalmente de compostos orgânicos menos voláteis, a partir da redescoberta da técnica na década de $1930^{[3]}$. Por que as separações com amostras gasosas ou vaporizadas não podem ser separadas com um fluxo de gás inerte? É provável que, novamente, as opiniões de um dos mais importantes físico-químicos alemães tinham influenciado muito esta ocorrência. O Professor Arnold Eucken (1884-1950) da Universidade de Göttingen sugeriu, em várias ocasiões, que o uso de um gás para eluição não seria possível, devido ao problema de difusão longitudinal que, ele pensava, induziria a reintegração de quaisquer componentes separados, não permitindo manter a separação das moléculas em moção rápida na fase gasosa. Este pensamento atrasou o desenvolvimento de cromatografia gás-sólido por eluição ${ }^{[4]}$.

$\mathrm{O}$ primeiro grupo de pesquisa que aplicou eluição com um gás inerte em sistema fechado foi o do Professor Gerhard Hesse (1908-1997) (Figura 1). Hesse obteve seu doutorado em química orgânica (ênfase em produtos naturais) na Universidade de Munique em 1937, tendo participado dos experimentos que conduziram à implantação da cromatografia líquido-sólido nesta universidade, logo depois da sua "redescoberta" em Heidelberg pelo grupo de $\mathrm{Kuhn}^{[3]}$. Hesse iniciou sua carreira acadêmica na Universidade de Marburg/Lahn. Seus interesses nesta época focalizaram a determinação de ácidos e ésteres extraídos de diversas plantas e sua ferramenta preferida foi a cromatografia líquido-sólido. Por outro lado, os ácidos mais voláteis não foram retidos suficientemente na separação empregando esta técnica. Ele propôs o uso de uma fase móvel gasosa, menos interativa com a fase estacionária, entretanto, quando discutiu

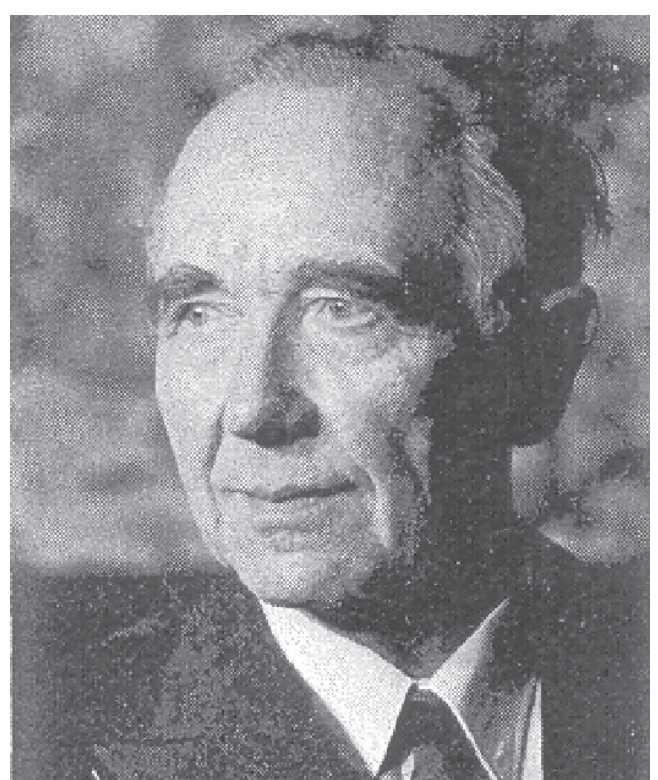

Figura 1 Foto de Gerhard Hesse.

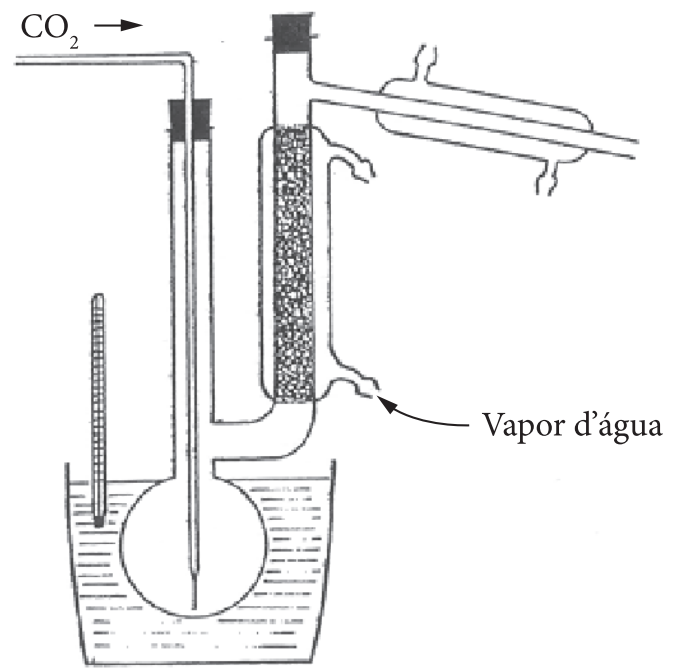

Figura 2 O primeiro sistema fechado utilizado por Hesse et al. para a cromatografia gás-sólido (modificado de Hesse et al. ${ }^{[6]}$ ).

esta ideia com colegas, as suas respostas foram negativas; citando o problema da difusão longitudinal na fase móvel gasosa.

Hesse decidiu fazer um experimento simples para verificar se a difusão apresentava os problemas levantados. Recheou uma coluna de vidro com amido, adicionou uma mistura de iodo e bromo no seu topo e, com a entrada fechada, passou um fluxo de nitrogênio através 
da coluna. Logo se formaram duas bandas que se mantiveram separadas durante todo o experimento, uma de cor marrom (bromo) e outra azul (iodo), comprovando, pelo menos para Hesse, que cromatografia empregando uma fase gasosa inerte para eluição era viável ${ }^{[5]}$.

Hesse e seus alunos montaram colunas de sílica, colocando a fase estacionária no centro de um condensador (Figura 2). A água ou outro líquido, circulando no condensador, aqueceu a coluna, quando desejado. A injeção foi realizada por destilação e a fase móvel usada foi dióxido de carbono. As substâncias eluídas foram coletadas em pequenos frascos resfriados para identificação e para determinações das suas propriedades físicas. Com este sistema, ele e seus alunos separaram alguns ésteres voláteis que não haviam sido separados por destilação, na ausência do recheio do condensador ${ }^{[6]}$.
Uma vez comprovado que seu sistema simples, com gás de arraste para levar os componentes separados para o coletor de frações, funcionava, um novo sistema, incorporando os conceitos do anterior, entretanto muito mais reprodutível, foi construído (Figura 3). Com este sistema Hesse e Tschachotin ${ }^{[7]}$ separaram substâncias com pontos de ebulição muito similares, misturas azeotrópicas, isômeros cis e trans de dicloroeteno, e diversos ácidos voláteis, saturados e insaturados. Tomaram a precaução de verificar que o aquecimento da coluna não induzia modificações na composição dos eluatos, não encontrando nenhum problema. Deve ser enfatizado que, neste trabalho ${ }^{[7]}$, os autores descreveram seu novo método de separação como "uma modificação da análise por adsorção de Tswett", claramente reconhecendo o processo cromatográfico envolvido.

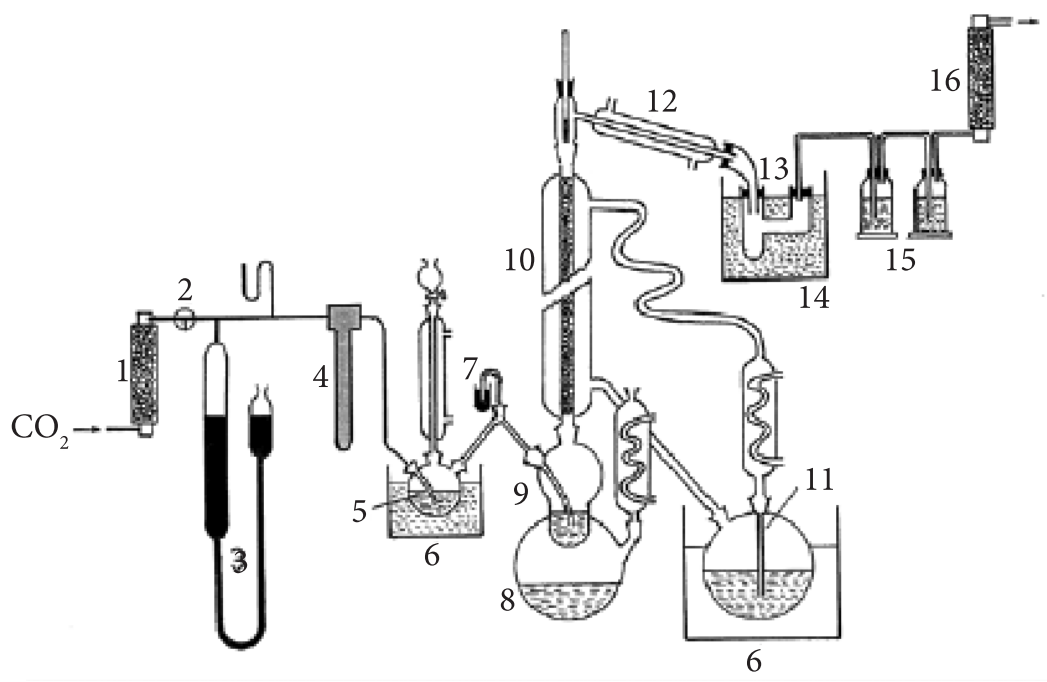

Figura 3 Outro sistema de cromatografia gás-sólido de Hesse et al. 1 = adsortivo para limpeza da fase móvel $\left(\mathrm{CO}_{2}\right) ; 2$ = torneira de três vias; 3 = medidor de pressão de mercúrio; 4 = medidor da vazão da fase móvel; 5 = sistema para modificar a composição da fase móvel, quando desejado; 6 = banhos para controlar a temperatura; 7 = frasco com mercúrio, para controlar a pressão interna do sistema; $8=$ sistema contendo vapores à temperatura constante; $9=$ frasco com a amostra, que será volatilizada por aquecimento, para a injeção; 10 = coluna de separação, recheada com a fase estacionária; 11 = sistema para produzir os vapores utilizados para controlar a temperatura da coluna; 12 = condensador para condensar as frações voláteis separadas; 13 = sistema de aprisionamento das frações condensadas (trocado com frequência); $14=$ frasco de resfriamento do sistema de aprisionamento; 15 e 16 = soluções e sólidos para absorver o gás de arraste e seus aditivos (modificada de Hesse et al. ${ }^{[7]}$ ). 
Em 1943, Hesse foi chamado pelo exército alemão (ele participou na campanha contra a União Soviética durante a segunda guerra mundial) e, na volta, transferiu-se para a Universidade de Freiburg/Breisgau e, logo depois, para a Universidade de Erlangen/Nürnberg, onde estabeleceu um programa para treinamento de alunos e técnicos em diversas técnicas cromatográficas, incluindo as que utilizam gases com fases móveis.

Gerhard Damköhler (1908-1944) doutorou-se na Universidade de Munique em1931 e, depois de um período na indústria Linde, tornou-se assistente do Prof. Eucken em Göttingen. Em 1937, Damköhler transferiu-se para o Departamento de Engenharia Química do Instituto de Pesquisas da Força Aérea Alemã em Braunschweig, continuando suas pesquisas abordando reações rápidas em fase gasosa. Como parte destes estudos, Damköhler realizou experimentos envolvendo a separação de vapores de diferentes misturas de líquidos voláteis por adsorção-dessorção, utilizando nitrogênio como gás de arraste, um dispositivo para vaporizar a mistura líquida injetada e um detector por condutividade térmica. A Figura 4 mostra duas separações, entre várias, publicadas por ele ${ }^{[8,9]}$. Nestes trabalhos, Damköhler e Theile indicaram especificamente que o problema de difusão longitudinal não foi encontrado e que a cromatografia por adsorção de gases/vapores era um processo que merecia ser explorado.

Outro colaborador do Prof. Eucken, Ewald Wicke (1914-2000), continuou na Universidade de Göttingen após seu doutorado e, depois da morte do Prof. Eucken, em 1950, ocupou a cadeira dele, transferindo-se para a Universidade de Hamburgo em1954 e completando sua carreira na Universidade de Westphalia, em Munster, a partir de 1959. Wicke também realizou experimentos que indicaram que a difusão longitudinal poderia ser controlada, como indica a Figura 5. Atualmente, sabe-se que o objetivo deste estudo não foi obter separação e sim fazer uma comparação do comportamento de duas substâncias injetadas separadamente e misturadas. As
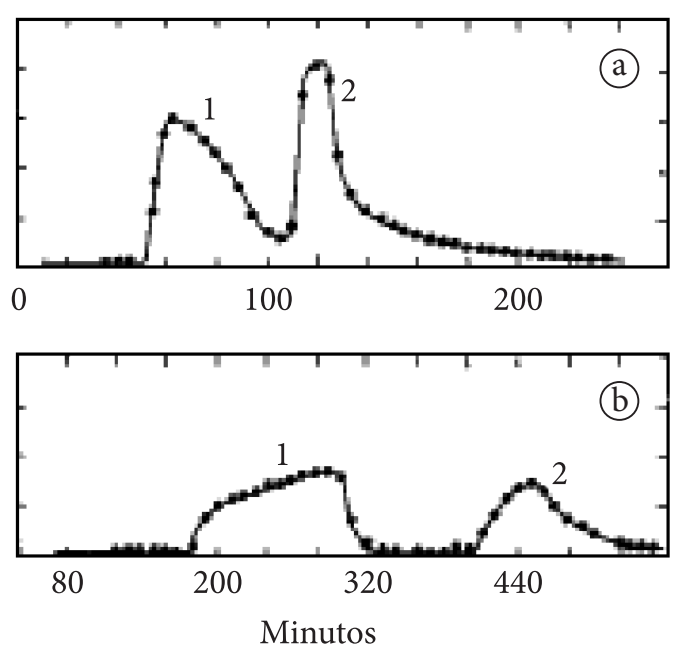

Figura 4 Alguns cromatogramas apresentados por Damköhler e Theile. A fase estacionária foi terra de pistoleiro e a fase móvel foi nitrogênio. $O$ volume de injeção foi $0,1 \mathrm{~mL}$ da mistura líquida e o detector foi o de condutividade térmica. a: separação de metanol (1) e etanol (2) a $0{ }^{\circ} \mathrm{C}$; b: separação de cicloexano (1) e benzeno a $-40^{\circ} \mathrm{C}$ (modificado de Damköhler et al. ${ }^{[8]}$ ).

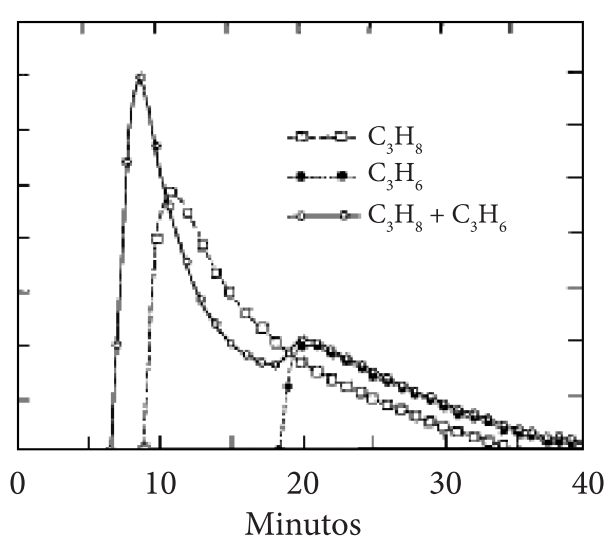

Figura 5 Cromatogramas obtidos por Wicke para propano $\left(\mathrm{C}_{3} \mathrm{H}_{8}\right)$ e propeno $\left(\mathrm{C}_{3} \mathrm{H}_{6}\right)$ injetados separadamente e misturados. Coluna: $57,5 \mathrm{~cm} \times 4,2 \mathrm{~mm}$; fase estacionária: bauxita granulada; fase móvel: ar a $60 \mathrm{~mL} / \mathrm{min}$; volume do gás injetado: $30 \mathrm{~mL}$ dos gases individuais e $60 \mathrm{~mL}$ da mistura 1:1 (v/v) (modificado de Ettre $\left.{ }^{[4]}\right)$. 
duas substâncias mostraram comportamentos similares, quer injetadas individualmente, quer misturadas, isto é, a presença de um segundo componente não tem muito influência na adsorção-dessorção do primeiro componente ${ }^{[10]}$.

$\mathrm{Na}$ década de 40 do século vinte, na Inglaterra, o pesquisador Eugene Glueckauf (1906-1982) aplicou a cromatografia gás-sólido a temperaturas baixas para a separação dos gases inertes produzidos pela fissão de urânio, especificamente criptônio e xenônio, como ferramenta para medir a eficiência de diferentes fontes de nêutrons que induziam a fissão. Em um congresso de cromatografia, organizado pela Sociedade Faraday em 1952, foi descrito o uso de $5 \mathrm{~g}$ de carvão pulverizado (diâmetro médio das partículas de $0,025 \mathrm{~cm}$ ) como fase estacionária, em uma coluna de $20 \mathrm{~cm}$ e eluição com hidrogênio, inicialmente a $-45^{\circ} \mathrm{C}$, para quantificar o criptônio, e depois a $50{ }^{\circ} \mathrm{C}$ para medir o xenônio ${ }^{[11]}$. A espectrometria de massas das frações separadas indicou a presença de menos de $0,1 \%$ de criptônio no xenônio coletado, comprovando a eficiência da separação. Ele aplicou uma equação para calcular o número de pratos da coluna, obtendo 500 pratos. O número de pratos aumentou quando a vazão do gás de arraste aumentou, sugerindo que a difusão longitudinal poderia ter um efeito em vazões baixas. Detalhes desta e de outras separações foram descritas alguns anos mais tarde ${ }^{[12]}$, quando os resultados obtidos por vários pesquisadores, durante a Segunda Guerra Mundial, foram liberados para publicação.

$\mathrm{Na}$ União Soviética, alguns pesquisadores também realizaram experimentos empregando a cromatografia em fase gasosa inerte, na década de 50. Um destes experimentos foi feito pelo grupo de M.N. Turkeltaub, da Universidade de Moscou, que separou diversos hidrocarbonetos voláteis, utilizando uma coluna de sílica e ar como fase móvel. Colocaram a mistura em uma das extremidades da coluna e, após iniciar o fluxo de ar, aqueceram a coluna com um forno móvel, que passou lentamente do lado mais próximo ao local da aplicação da amostra até sua saída. Foi dado o nome "cromatotermografia" a esta técnica ${ }^{[13]}$.

A década de 40 do século passado foi tumultuada, sendo a maior parte dela marcada pela Segunda Guerra Mundial. Sendo assim, revistas científicas não foram publicadas com regularidade ou tiveram suas publicações atrasadas. Além disso, a maioria não foi distribuída, exceto no local de publicação. Sendo assim, pesquisas realizadas nos países sob controle dos alemães não foram conhecidas nos países aliados, como os Estados Unidos e Grã-Bretanha (e Brasil) e vice-versa, até depois de 1946. A partir desta data, resultados científicos dificilmente foram comunicados entre o "Oeste" e os países sob controle da União Soviética. O resultado destas barreiras foram vários desenvolvimentos paralelos, sem que um grupo tivesse conhecimento dos trabalhos dos outros. Estes fatos influenciaram os anos iniciais da cromatografia gás-sólido, inclusive a construção de sistemas mais adequados para este fim, tópico a ser tratado no próximo capítulo.

\section{Referências}

1 Collins CH. Precursores da cromatografia gás-sólido. Scientia Chromatographica 2011; 3(4):281-288.

2 Collins CH. Michael Tswett e o "nascimento" da cromatografia. Scientia Chromatographica 2009; 1(1):1-21.

3 Collins $\mathrm{CH}$. Químicos redescobrem a cromatografia líquido-sólido. Scientia Chromatographica 2009; 1(2):7-11.

4 Ettre LS. Early evolution of gas adsorption chromatography. Part I: Displacemnt development and the beginnings of elution-type investigations. Chromatographia 2002; 55:497. http://dx.doi.org/10.1007/ BF02492283 
5 Gerhard E. Hesse. In: "75 years of chromatography - a historical dialogue”. Ettre LS, Zlatkis A, editors. Amsterdam: Elsevier; 1979. vol. 17, p. 131-140.

6 Hesse G, Eilbracht H, Reicheneder F. Das krystallisierte Calotropis-Harz. III. Mittreilung über afrikanische Pfeigifle. Justus Liebig's Annalen der Chemie 1941; 546:233. http://dx.doi.org/10.1002/jlac.19415460302

7 Hesse G, Tschachotin B. Adsorptionanalyse von Gasen und Dämpfen. Naturwissenschaften 1942; 30:387. http://dx.doi.org/10.1007/BF01475303

8 Damköhler G, Theile H. Stofftrennung durch Adsorption aus einem Hilfsgasstrom (Auszug). Der Chemie 1943; 56:353. http://dx.doi.org/10.1002/ ange. 19430565103
9 Damköhler G, Theile H. Güte der Sorptionverfahren zur Gastrennung (Auszug). Der Chemie 1943; 56:354. http://dx.doi.org/10.1002/ange.19430565104

10 Wilke E. Zur Zerlegung von Gasgemischen in durchströmter Adsorberschicht. Angewandte Chemie 1947; B19:15.

11 Glueckauf E. Discussion. The Analyst 1952; 77:903.

12 Glueckauf E, Kitt GP. The krypton and xenon contents of atmospheric air. Proceedings of the Royal Society of London 1956; A234:557.

13 Wintermeyer U. Historical review. In: Unger KK, editor. Packings and Stationary Phases in Chromatographic Techniques. New York: Marcel Dekker; 1990. cap. 1.

Recebido: 12/03/2012

Aceito: 21/03/2012 